\title{
E-voting and electoral participation
}

\author{
Alexander H. Trechsel \\ European University Institute, Florence and University of Geneva
}

\begin{abstract}
Numerous studies show that, together with the United States, Switzerland presents the lowest average levels of turnout among established democracies. At the same time, Swiss voters are among those most frequently called to the polls, owing to the widespread possibilities for direct democracy on all three levels of the federal state. Not surprisingly, it is also in Switzerland that new means of political participation and in particular remote voting techniques via postal mail or over the Internet - have been promoted, tested and implemented most prominently. In this paper we will try to empirically assess a number of hypotheses on the role and impact of new means of participation in referendums. In doing so, we will focus on data stemming from a recent referendum vote where a multi-channel approach for participation was chosen. In September 2004, and after several pilot votes on the communal level, the Swiss canton of Geneva offered over 20'000 citizens the possibility to cast their votes over the internet in a federal referendum. For the first time in the world, parts of the electorate were able to cast their votes through remote internet voting for a binding decision on the national level. Accompanying the introduction of e-voting mechanisms in the canton of Geneva, we designed a survey questionnaire that was answered by over 1'000 non-voters, voters at the ballot box, postal voters and evoters. Thanks to this data this contribution tries to shed some further light on the potential effects of e-voting on turnout. Additionally, this contribution will try to measure possible distortions - induced by this new channel of participation - of the electorate's political choice at the polls.
\end{abstract}

\section{Introduction}

Numerous studies show that, together with the United States, Switzerland presents the lowest average levels of turnout among established democracies (Franklin 2004). At the same time, Swiss voters are among those most frequently called to the polls, owing to the widespread possibilities for direct democracy on all three levels of the federal state (Kriesi and Trechsel 2005). Not surprisingly, it is also in Switzerland that new means of political participation - and in particular remote voting techniques via postal mail or over the Internet - have been promoted, tested and implemented most prominently. In 1998, the Federal government launched an e-voting initiative in which it invited three cantons (Geneva, Zurich and Neuchâtel) to lead pilot projects in this 
field. The authorities of the Canton of Geneva developed an e-voting platform complementing the two traditional channels of participation, namely voting at the ballot box and voting via postal mail, introduced as an automatic feature ${ }^{1}$ in 1995. Though technologically compatible with elections, it was decided to limit the scope of the system to referendums, at least for the initial implementation stage.

A survey, conducted at an early stage in the project, could show that the idea of providing a supplementary channel for voting over the internet was strongly supported by the electorate: Over three-quarters of the electorate were in favour of the introduction of such a new system in the Canton of Geneva (Kies and Trechsel 2001: 64). In a second survey, over 400 randomly chosen citizens were asked to test an alpha-version of the internet-voting platform. Face-to-face interviews were conducted before and after the citizens' exposure to the alpha-version. The results were very clear: voters that initially favoured the introduction of e-voting remained convinced about its desirability after having tested the module. More importantly, a large part (40 percent) of those that oppose e-voting before testing the module subsequently favoured its introduction (see Christin and Müller 2002, Trechsel et al. 2003: 187 f.). In short, one could measure a strong desirability in favor of e-voting among the electorate, leading the Cantonal Chancellery to implement the system incrementally. On 19 January 2003 the 1'162 potential voters of the small commune of Anières were given the opportunity to cast their over the internet in a legally binding referendum. Since then, a total of seven votations have been held in an ever growing number of communes. In the most recent ballot (November 2004), the citizens of eight communes (totaling a number of $41^{\prime} 000$ potential voters) were given the right to vote via the internet.

In this contribution we will try to assess the impact of this new channel of voting on turnout (section 2). Here, we will focus on e-voting as an independent variable and measure its effect on participation, using both aggregate data and individual level

\footnotetext{
${ }^{1}$ Voters may cast their vote by physically going to the polling station on the Sunday morning of the voting weekend. Since 1991 postal voting became possible but required the voter to make an explicit demand to the elections administration for the possibility to use this procedure. Since 1995, the voting material is sent automatically to every voter, without prior registration needed, three weeks before the voting weekend. It contains a voting card (ID), the ballot paper as well as the voting pamphlet edited by the government. Over this three week period voters are able to return the envelope containing the signed voting card and the ballot card. It has to reach the elections administration by the Saturday morning of the voting weekend. If this deadline is missed only voting at the polling station is possible.
} 
data stemming from a survey conducted in the aftermath of a referendum held in September 2004 and in which the four communes of Anières, Carouge, Cologny and Meyrin offered their electorate the possibility of e-voting. In section 3 we will turn our attention to the explanation of the mode of participation chosen by the voters in the September 2004 ballot before using e-voting again as an independent variable for measuring its potential impact on the direction of the vote (section 4).

\section{Access to the ballot box and turnout: the effects of postal and electronic voting over the Internet}

The question of why voters turn out in democratic elections and referendums is central to a large literature on political behaviour. Myriad models have been conceptualized, specified and estimated over the past decade, embedded within fullfledged theories that try to shed some light on one of the fundamental questions posed to the social sciences: why is it that some citizens vote while others abstain? It is by no means our purpose to develop yet another model of political participation, but rather to focus on one limited factor that is recurrent in most models: the cost of participation.

Following the application of rational choice approaches, and guided guided by the seminal works of Downs (1957), Olson (1965), Riker and Ordeshook (1968) and others, it became clear that political participation implied both costs and benefits. In particular, it is undisputed that the sheer act of voting causes certain costs to the voter, be they immaterial in form (e.g. time spent for gathering information and casting the vote) or material (e.g. money spent for going to the polling booth or sending in the ballot). We know that the variance in costs is not in itself sufficient to explain why citizens vote or abstain. However, it remains sound to hypothesize a potential link between the citizens' accessibility to the ballot box and their participation: all other factors being held constant, the lower the costs of participation, the higher the probability of participation.

In order to further specify this hypothesis we will focus on mechanisms that allow voters to reduce their costs of participation, in particular the introduction of remote voting (also known as absentee voting in the Anglosaxon context). One of the classic forms of remote voting is postal voting, enabling voters to cast their votes without 
having to physically go to the ballot box. Instead, voters are allowed to send in their ballots via postal mail. From a theoretical perspective, such an improved access to the ballot box should only have positive effects on turnout - or has it? Cross-national studies usually corroborate this hypothesis, but not always. In a recent analysis of turnout over space and time, based on data from twenty-two countries over half a century Franklin (2004) finds that a theoretically relevant variable measuring access to the ballot box, absentee voting, does not produce the expected effect on turnout when it is introduced:

\begin{abstract}
"Absentee voting, though it appears to distinguish between countries with higher and lower turnout (as has also been found in past research), does not appear to cause turnout to rise when it is introduced in a country that previously did not provide for absentee ballots. To the contrary, the introduction of postal voting ballots appears to be associated with falling turnout, quite contrary to expectations." (Franklin 2004: 156 f.)
\end{abstract}

This counterintuitive finding calls for further explanation. Franklin provides such an explanation by stating that the negative relationship may be produced by a causal misspecification of the relationship between turnout levels and the introduction of postal voting. According to Franklin (2004: 148), the problem lies in the fact that absentee voting is sometimes introduced - as in Switzerland - primarily for curing poor turnout. Therefore, the effects of introducing postal voting "may simply be overwhelmed by whatever circumstances were already causing turnout to fall in the country concerned" (Franklin 2004: 148).

In our view, such an explanation, as tempting as it is, does not hold for two reasons. First, underpinning Franklin's analysis is the assumption that introducing postal voting would necessarily have to increase turnout for the variable to remain in his subsequent models - which it doesn't. Precisely because such measures are often introduced in contexts of low and falling turnout levels, such an expectation may be simply too ambitious. Franklin's analysis produces negative, non-significant effects of absentee voting on turnout. However, his cross-sectional time series analysis cannot detect whether in the absence of the introduction of postal voting turnout would not have fallen even more rapidly. In other words it may well be that the reduced cost of 
participation through the introduction of postal voting does not necessarily reverse, but slow down or even neutralize trends of falling turnout.

Second, Franklin's analysis suffers from a different form of misspecification than the one he mentions (inverse causality), namely by treating "absentee voting" as a dichotomous variable (it is either present or absent). This is, however, a serious oversimplification that is likely to produce spurious results. Let us draw the attention to two major problems in cross-national analyses treating "absentee voting" as a dichotomous variable. First, "absentee voting" can take on numerous and significantly different forms. They range from

- physically voting at the post office (Sweden) to voting from any mailbox (Switzerland):

- from postal voting as an alternative (in most cases) to exclusive postal voting (Oregon);

- from postal voting where voters have to pay for the stamp (in the early stages in Switzerland) to free-of-charge postal voting (contemporary Switzerland);

- from conditional, two-stage postal voting (some cantons) to unconditional, automatic postal voting;

- from short postal voting periods to longer ones;

- from longstanding experiences with postal voting (Switzerland) to pilot runs (UK).

Second, in the same election "absentee voting", particularly in federal systems, may not take on the same form from one constituency to the other (e.g. from one Swiss canton to the other or from one US State to the other). Put differently, "absentee voting" as a dichotomous variable fails to capture large variances both concerning its particular design and its intra-national specificities.

Not surprisingly then, from having a closer look at these variations one will find effects of different magnitudes. In systems where postal voting is offered unconditionally and free of charge - as a supplementary means for participation and over a period of several years (such as in Switzerland), empirical results usually show significant and positive effects on turnout (Wernli 2001). Data from the Canton 
of Geneva show (almost) systematically higher levels of turnout than the Swiss mean ever since automatic postal voting has been introduced in 1995 (Figure 1).

Figure 1: The effect of the introduction of automatic postal voting in the canton of Geneva

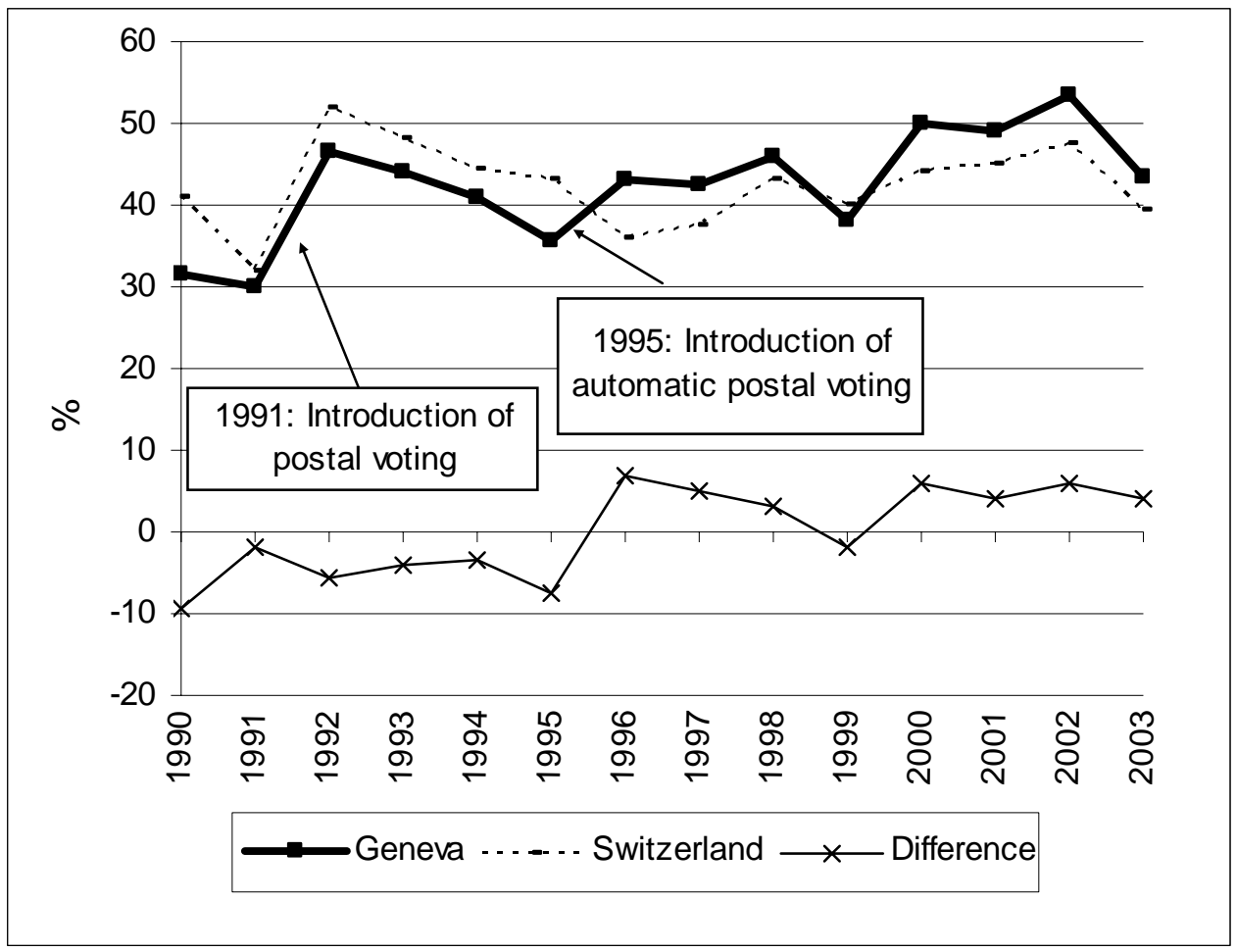

Even in systems where postal voting has entirely replaced voting at the ballot box (Oregon), the effects on turnout are significant and positive (Southwell 2004, Karp and Banducci 2000). In pilot runs, such as the 2003 local elections in the UK, Norris (2005) could show a similarly positive and highly significant impact of automatic postal ballots on turnout.

To sum up, we argue that cross-national comparisons of complex voting mechanisms and the changes the latter induce over time have to be studied more carefully if we believe that both design and context matter. Central to this contribution is the claim that the same applies to the recent developments in the field of remote electronic voting. Gibson (2005) conceptualizes a large range of e-voting mechanisms and techniques, from which a series of hypotheses on the non-uniform impact of e-voting on turnout may be derived. 
From a theoretical perspective, the strength of this (hypothetical) relationship may be affected by the institutional context in which elections or referendums are held. For example, in contexts where the voters are called to the polls on a very frequent basis (e.g. in Switzerland), the added value of lowering the costs for democratic participation may be more salient than in low-frequency electoral contexts. Furthermore, interaction effects with pre-existing voting channels may prove important in several ways. First, the force of the relationship may vary depending on previous experiences with other forms of remote voting, such as postal voting. In contexts where postal voting has become a standard channel of participation, the added value of remote e-voting over the Internet ${ }^{2}$ may be lower than in contexts where all voters previously had to show up physically at the ballot box. A competing hypothesis would be that in a polity where remote postal voting has been previously implemented, additional remote voting techniques may encounter less skepticism among the electorate, hence generating faster uptake. Second, if introduced simultaneously, postal voting may initially be favored over remote e-voting as it procures similar levels of convenience but is based on traditional means of communication, which is precisely what was found in the UK pilot elections of 2003 (Norris 2005). Thirdly, whether e-voting is introduced as a complementary means of participation (i.e. not abolishing traditional channels) or as a replacement for other forms of remote voting (i.e. as postal voting) may make a difference. Theoretically speaking, if e-voting is simply added to the panoply of voting procedures, it is difficult to imagine negative effects on turnout, unless there is a serious misspecification in the model. If proposed as an additional feature, e-voting cannot, logically, produce negative effects but only, at worst, remain neutral in its effect on turnout.

Let us now turn to the empirical assessment of the effects of remote e-voting on turnout in the context of the Canton of Geneva's pilot project on internet voting. In the survey mentioned in the introduction to this contribution, the authors found a large proportion of non-voters and occasional voters who expressed a subjective and prospective propensity to participate more regularly in democratic votes should evoting be provided. The overall estimation, based on the survey results, predicted a nine-percent increase of turnout through the simple addition of e-voting to the

\footnotetext{
${ }^{2}$ We from now on refer to e-voting or internet voting as remote forms of voting by contrast of electronic voting systems at the polling places.
} 
previously existing voting channels (Kies and Trechsel 2001: 54). To test this prediction on the basis of aggregate data is difficult, if not impossible. However, analogous to the logic behind Figure 1, we can compare the mean differences in turnout between the communes that offered e-voting to their electorate and the cantonal mean before and after the introduction of e-voting.

Table 1: Mean differences in turnout in percentages ( $n=$ number of votations)

\begin{tabular}{lrrrr}
\hline Period (n) & Anières & Carouge & Cologny & Meyrin \\
\hline 2001-04, without e-vote (11) & 6.13 & -1.10 & 8.87 & -1.32 \\
2004, with e-vote (2) & 5.97 & -1.20 & 6.66 & -3.93 \\
\hline Difference (e-vote - non-e-vote) & -0.16 & -0.10 & -2.22 & -2.60 \\
\hline
\end{tabular}

Source: Service des votations et des elections, Canton of Geneva

In the first row of Table 1 we calculated the difference between the cantonal mean in turnout for eleven votations held between 2001 and 2004 and the mean turnout for these votations in the four communes of Anières, Carouge, Cologny and Meyrin that subsequently offered e-voting to their respective electorates. The results indicate that the two smaller communes, Anières and Cologny, had average turnout levels superior to the cantonal mean (6.13 percent in Anières and 8.87 percent in Cologny), while the inverse is true for the larger communes of Carouge and Meyrin (-1.1 percent and -1.32 percent respectively). The second row of Table 1 contains the difference of the mean turnout in these communes from the cantonal mean, once evoting was introduced. We took into consideration the two federal votations of September and November 2004 in which all four communes offered the possibility to cast a vote over the internet to the electorate. The difference between the values in both rows tells us whether the two e-enabled votations of 2004 showed higher turnout levels than those traditionally observed in these communes. While the differences in turnout are not enormous, varying from -0.1 to -2.6 percent, we nevertheless must take into consideration the negative sign preceding these figures. In other words: the four communes under consideration showed lower turnout rates once e-voting was introduced.

It is at this point that we should be extremely careful in the interpretation of such an unexpected result. As argued earlier, the latter cannot be caused by the introduction of e-voting, the negative relationship being, for logical reasons, excluded from the 
valid categories of results. In other words, all we can say is that for these two votations the commune's difference in turnout from the cantonal mean was more negative than for the eleven preceding votations. Full stop. If the relative turnout levels in these communes have decreased, then this must be caused by other reasons. At the same time, we cannot observe the same, structural effect on turnout as we have observed for postal voting (Figure 1). One may, however, object to this by pointing out the very low number of cases, as we can only consider two e-enabled votations that, in addition, took place within a very short lapse of time (two months). In other words: these results prevent any form of immediate enthusiasm concerning some turnout-boosting effect of e-voting, but one needs to adopt a longer term perspective in order to solidify such a statement based on aggregate data.

Fortunately we also dispose of yet unreleased individual data, which allows us to dig further into the question of political participation and e-voting. Following the four federal and two cantonal referendums that were held on 26 September 2004, Thomas Christin and myself could design and conduct a representative survey of voters and non-voters in the four e-voting-enabled communes. ${ }^{3}$ Table 2 shows a comparison between the aggregate data on modes of participation and our survey data.

Table 2: Modes of participation in the votations of September 262004

\begin{tabular}{|c|c|c|c|}
\hline \multirow{2}{*}{$\begin{array}{l}\text { Mode de } \\
\text { participation }\end{array}$} & \multicolumn{2}{|c|}{ Survey } & \multirow{2}{*}{$\begin{array}{c}\text { Real } \\
\text { turnout } \\
\text { in } \%\end{array}$} \\
\hline & $\%$ & $\mathrm{~N}$ & \\
\hline by postal mail & 72.8 & 416 & 72.5 \\
\hline by internet & 21.6 & 123 & 21.8 \\
\hline at the ballot-box & 5.7 & 32 & 5.7 \\
\hline total & 100 & 571 & 100.0 \\
\hline
\end{tabular}

Sources: Survey of September 262004 referendums and http://www.ge.ch/chancellerie/conseil/2001-2005/informations/chan040926.html

\footnotetext{
${ }^{3}$ Our sample comprises 1'014 respondents. The number of respondents of the two smaller communes have been oversampled, offering the tripe advantage of decreasing selection biases, increasing the precision of the results in these communes and allowing for separate (commune-by-commune) analyses of the data. The overall confidence interval was \pm 3.1 percent for a value of 50 percent and a confidence level of 95 percent. The subsequent results are stemming from the analyses undertaken by Christin and Trechsel (2005).
} 
Table 2 shows, besides the respectable fit between real turnout figures and our survey results, that postal voting is, by over 70 percent, the preferred mode of participation, followed by internet voting (21.8 percent) and voting at the ballot box (5.7 percent). ${ }^{4}$ We will come back to this in the following section. Let us first concentrate on the mobilizing potential of e-voting that can be assessed by our individual level data. In Table 3 we produce a cross-tabulation of the variables measuring the usual voting frequency of the respondents with their choice of the mode of participation in the September 262004 referendums.

Table 3: Modes of participation and usual voting frequency

\begin{tabular}{l|rrrrrr}
\hline Actual vote... & \multicolumn{6}{|c}{ Usual voting frequency... } \\
\cline { 2 - 7 } & always & often & $\begin{array}{c}\text { from } \\
\text { time to } \\
\end{array}$ & \multicolumn{7}{|c}{ time } \\
& $4.5 \%$ & $4.9 \%$ & $15.4 \%$ & $16.7 \%$ & $33.3 \%$ & $5.7 \%$ \\
at the ballot-box & $76.8 \%$ & $68.9 \%$ & $53.8 \%$ & $0.0 \%$ & $66.7 \%$ & $72.6 \%$ \\
by postal mail & $18.7 \%$ & $26.2 \%$ & $30.8 \%$ & $83.3 \%$ & $0.0 \%$ & $21.7 \%$ \\
by internet & $100.0 \%$ & $100.0 \%$ & $100.0 \%$ & $100.0 \%$ & $100.0 \%$ & $100.0 \%$ \\
\hline total $(\mathrm{n})$ & $(396)$ & $(122)$ & $(39)$ & $(6)$ & $(3)$ & $(566)$ \\
\hline
\end{tabular}

Source: Survey of September 262004 referendums

Unfortunately, the number of respondents among those that rarely or never vote is very low (only nine out of 566). Note that while none of the usual abstentionist chose e-voting as a means of participation, five out of the six quasi-abstentionists were tempted by this channel in September 2004. Also, among the irregular voters (those who vote "from time to time") the proportion of e-voters (30.8 percent) is higher than the overall figure of e-voters (21.6 percent). The same is true for regular voters among which e-voters are represented by 26.2 percent. By contrast, e-voting is below the mean among those voters that declare themselves as always participating (18.7 percent). These results show that neither "hardcore abstentionists" nor modelcitizens participating on every occasion are likely to be seduced by the introduction of e-voting mechanisms. The mobilization potential of e-voting is, however, largest among occasional voters. Unfortunately, the low number of respondents prevents us

\footnotetext{
${ }^{4}$ Additional analyses have revealed that the proportion of internet voters does not vary strongly among the four communes. Also, the figures for internet voting are rather close, though slightly lower, than those found in the first e-voting-enabled votations previously held in each commune.
} 
from producing any statistically significant results. Nevertheless, the fact that not a single hardcore abstentionist could be mobilized by the introduction of internet voting shows that the large majority of convinced abstentionists probably does not refrain from voting because of the costs involved in the voting procedure. For making convinced non-voters turn out, changes in voting procedures are by no means sufficient.

Although it is probably too early to assess the impact of e-voting on the level of turnout, the mere fact that over one fifth of the voters choose this new channel indicates a significant change in the nature of political participation at the polls. In the following section we will try to explain where these voters come from and what factors are conducive to "go digital".

\section{Explaining modes of participation in a multi-channel voting process}

As the introduction of e-voting does not seem, for the moment, to attract significant numbers of new voters, the 20-or-so percent of e-voters must have switched their traditional mode of participation in favor of e-voting. Our data shows that the bulk of e-voters previously have been former postal voters (Table 4).

Table 4: Usual and actual modes of participation

\begin{tabular}{l|rrrr}
\hline Actual vote... & \multicolumn{4}{|c}{ Usual vote... } \\
\cline { 2 - 5 } & at the ballot-box & by postal mail & by internet & total (\%) \\
\hline at the ballot-box & $76.0 \%$ & $2.0 \%$ & $5.3 \%$ & $5.5 \%$ \\
by postal mail & $12.0 \%$ & $81.2 \%$ & $5.3 \%$ & $73 \%$ \\
by internet & $12.0 \%$ & $16.8 \%$ & $89.5 \%$ & $21.5 \%$ \\
\hline total & $100.0 \%$ & $100.0 \%$ & $100.0 \%$ & $100.0 \%$ \\
(n) & $(25)$ & $(501)$ & $(38)$ & $(564)$ \\
\hline
\end{tabular}

Table 4 shows that in September 2004, a large majority or voters remained faithful to their usual mode of participation, with, however, a non-negligible transfer of postal voters towards e-voting (16.8 percent). Let us also underline a strong loyalty of former e-voters to this mode of participation. ${ }^{5}$ Nine out of ten voters having used the internet for participating in earlier pilots and voting in September have renewed their

\footnotetext{
${ }^{5}$ Note that e-voting pilots have been conducted prior to the vote on September 262004 in all four communes.
} 
e-voting experience. It is only in ten percent of cases that a "first time curiosity" effect, or else poor satisfaction or prudence regarding the vote via the internet has caused a shift back towards traditional means of participation. Again, however, we have to be prudent ourselves as the number of cases in these categories are small. Also, we do not yet know whether this new mode of participation already is at its peak or if a longer term diffusion process is starting. When automatic postal voting was introduced in 1995, 70 percent of the voters used this mode of participation. Over time, this proportion grew to a stable 95 percent (Figure 2).

Figure 2: Diffusion of postal voting in the Canton of Geneva (1994-2003)

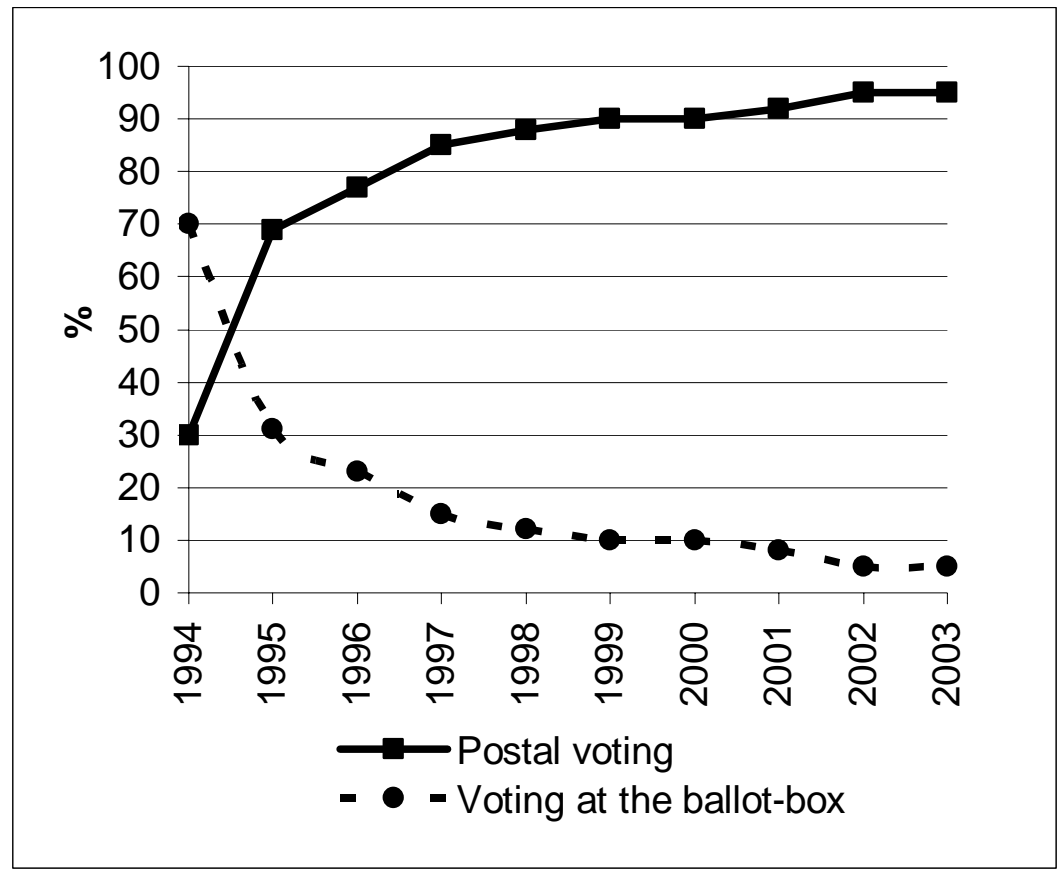

Data source: Service des votations et des elections, Canton de Genève

With regard to e-voting it is too early for hypothesizing possible diffusion processes, although what seems to be already clear is the fact that e-voters predominantly lower the proportion of postal voters rather than causing the disappearance of traditional voting at the ballot-box. The substitution effect of e-voting will therefore rather affect the former remote voting technique rather than replacing on-site participation.

This does not tell us whether the transfer of remote postal to remote internet voting is a neutral process, e.g. affecting all socio-economic categories of postal voters to a 
similar degree. In other words: besides choosing another mode of participation, are the demographic, socio-economic and even political profiles of internet voters significantly different from those of postal voters that remain faithful to this channel of participation? Both theories and empirical investigations in the field of the so-called "digital divide" have so far provided us with a better understanding of internet diffusion processes among and within societies (see for example Norris 2001). Socioeconomic and demographic variables, such as age, gender, education, occupational status, income and others have been found to exert a significant impact on the access to, and use of the internet in modern societies. Similarly, the use of the internet in politics is, according to this literature, linked to individual predispositions for traditional forms of civic engagement, information gathering etc. Finally, variables directly linked to ICTs, such as computer literacy and trust in new technologies may explain the variance in use of the internet.

Building on these insights, we hypothesize a non-neutral shift from traditional modes of participation to internet voting, affecting less the level of turnout but rather its nature. Aggregate data stemming from the electoral roles allow us, in a first stage, to compare the over- and under-representation of age groups and gender among voters. 
Figure 3: Differences in the weight of age and gender categories among voters compared to their real weight in the electorate (in percentage of the entire electorate; $n=22$ '137)

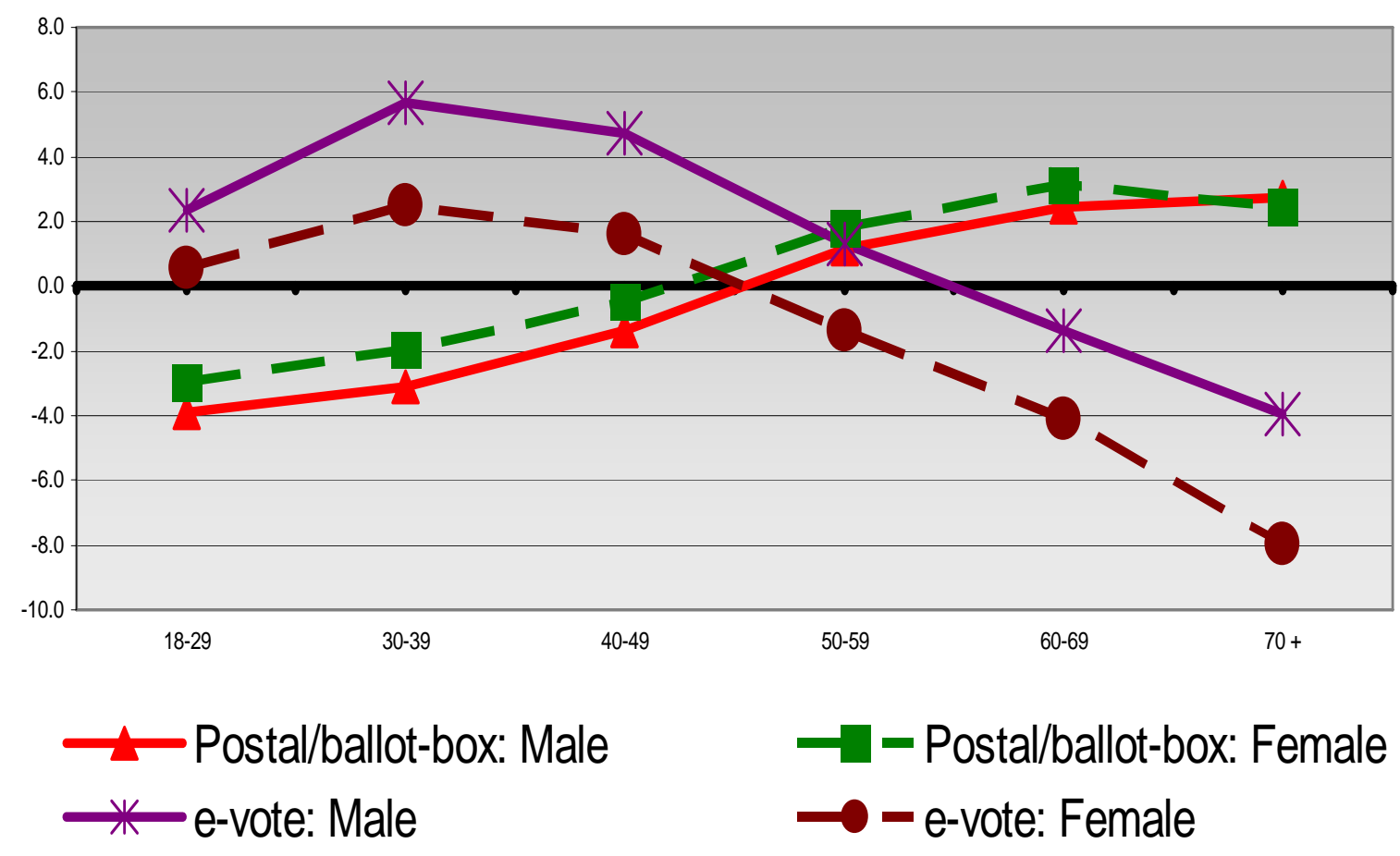

Figure 3 clearly shows that internet voting decreases with age, independently of gender. By contrast, traditional modes of voting increase with age, with voters above 50 years old being overrepresented. Finally, while traditional voting is rather genderneutral, male voters systematically use e-voting more frequently than their female counterparts.

Using our survey data, we have constructed three models - a socio-economic and demographic model, a political model and an ICT-model - in order to estimate the relative weight of our variables in the explanation of the mode of participation chosen. For reasons of space, we only present the results of our complete model (Table 5) combining the three partial models that can be found in the annex of this paper (see Tables A1 to A3 in the Annex).

Table 5: Complete model for the mode of participation (log. regression coefficients) 


\begin{tabular}{lccc}
\hline Independent variables & B & s.e. & sig. \\
\hline Age (in 10-year categories) & -.172 & .176 & .329 \\
Gender & -.092 & .250 & .712 \\
Level of education & .547 & .449 & .223 \\
Gross income of household & .186 & .096 & .054 \\
Left-right scale & -.094 & .250 & .706 \\
Political discussions & -.314 & .192 & .102 \\
Trust in political institutions & .195 & .300 & .515 \\
Trust in politicians & .356 & .305 & .243 \\
Trust in public authorities & .226 & .361 & .530 \\
Computer literacy & .612 & .253 & .015 \\
Frequency of internet use & .205 & .110 & .063 \\
Site of internet access & -.336 & .487 & .489 \\
Type of connection & $\mathbf{1 . 0 9 6}$ & .445 & .014 \\
Trust in information on the internet & -.117 & .362 & .747 \\
Trust in communications on the internet & -.720 & .307 & .019 \\
Trust in transactions on the internet & .322 & .226 & .154 \\
Trust in the e-voting procedure & $-\mathbf{1 . 2 3 4}$ & .345 & .000 \\
\hline Constant & -3.622 & 2.123 & .088 \\
\hline Pseudo $\mathrm{R}^{2}$ (Nagelkerke): .423; $\mathrm{n}=178 ;$ in bold $=$ sign. at $95 \%$ level &
\end{tabular}

When estimating the complete model, some of the significant effects that we found in the socio-economic and demographic model (Table A1 in the Annex) completely disappear. Neither age nor income continue to play a significant role in this complete model. Note, however, that the effect of income is almost statistically significant (we'll return to this point). All "political" variables remain insignificant and none can contribute to the explanation of choice of one mode of participation over the other. Finally, the only significant variables that we find are contained in the ICT-section of the complete model: the higher the computer literacy, the faster the internet connection, the higher the level of trust in communications over the internet and the higher the trust in the e-voting procedure itself, the higher the probability of a voter to prefer e-voting over traditional channels of participation.

We have estimated a number of supplementary models, omitting certain variables in order to test the robustness of the results. First, we have estimated a complete model omitting the variable "internet connection". Including this variable causes a large number of missing cases as it was only asked to those respondents having internet access from their homes. By omitting this variable we can increase the number of valid cases from 178 to 205 . In this model, all previously significant variables remain significant. However, the variable "gross income of household" and "frequency of 
internet access" become statistically significant. Second, we have estimated an alternative model omitting the most significant effect on the choice of the mode of participation, namely the level of trust in the e-voting procedure. One could criticize this variable by pointing out its potentially tautological character, biasing the other variable's coefficient estimates. However, omitting this variable does not change anything to the results found in the complete model. ${ }^{6}$

To sum up, our complete model shows that (unless we exclude the variable measuring the type of internet connection), all non-ICT-related effects disappear. In other words, neither age, nor gender, nor the level of education nor any of the political variables are statistically associated with the choice of internet voting. It is clearly trust in the e-voting procedure itself, in the communications over the internet, the rapidity of the internet access and computer literacy that contribute to the explanation of why voters opt for internet voting or, inversely, for traditional means of participation. This finding puts a question mark to some simple, if not simplistic explanations that have been proposed in the literature, in the media and by politicians. Although we know that women vote less frequently over the internet than men, although we know that e-voting is more popular among the younger segments of the electorate etc. our analysis could show that, at the end of the day, these variables are not very helpful for explaining why some voters choose their keyboard rather than their pencils for voting in direct democratic decisions at the polls. Rather, the choice of e-voting is above all dependent on the subjective attitudes of the individual voters - and their objective opportunities - linked to new information and communication technologies.

Finally, let us mention that among the variables measuring trust in the internet, trust in communications on the internet is the only statistically relevant factor. Neither trust in the information on the internet nor the latter's potential for transactions are of interest in this context. This is a rather counter-intuitive finding, as one would have expected an analogy between e-voting and other forms of transactions on the web, such as e-banking and other online-shopping features. However, this not being the case, one may formulate the hypothesis that voters seem to associate the act of

\footnotetext{
${ }^{6}$ The same is true if we omit this variable and, additionally, omit the variable measuring the type of connection. Here as well, income and the frequency of internet use become statistically significant.
} 
voting over the internet with a form of communications with the public authorities (and maybe even with their fellow citizens) rather than simply a transaction.

In conclusion, while the choice for internet voting is above all a choice against the traditional form of voting, i.e. postal voting. Determinants for this choice are above all linked to ICT-related factors. Furthermore, when directly asked what motivated their choice of voting over the internet, almost three quarters of the respondents spontaneously indicated the convenience factor (Figure 4).

Figure 4: Spontaneous reasons for having chosen internet voting $(n=123)$

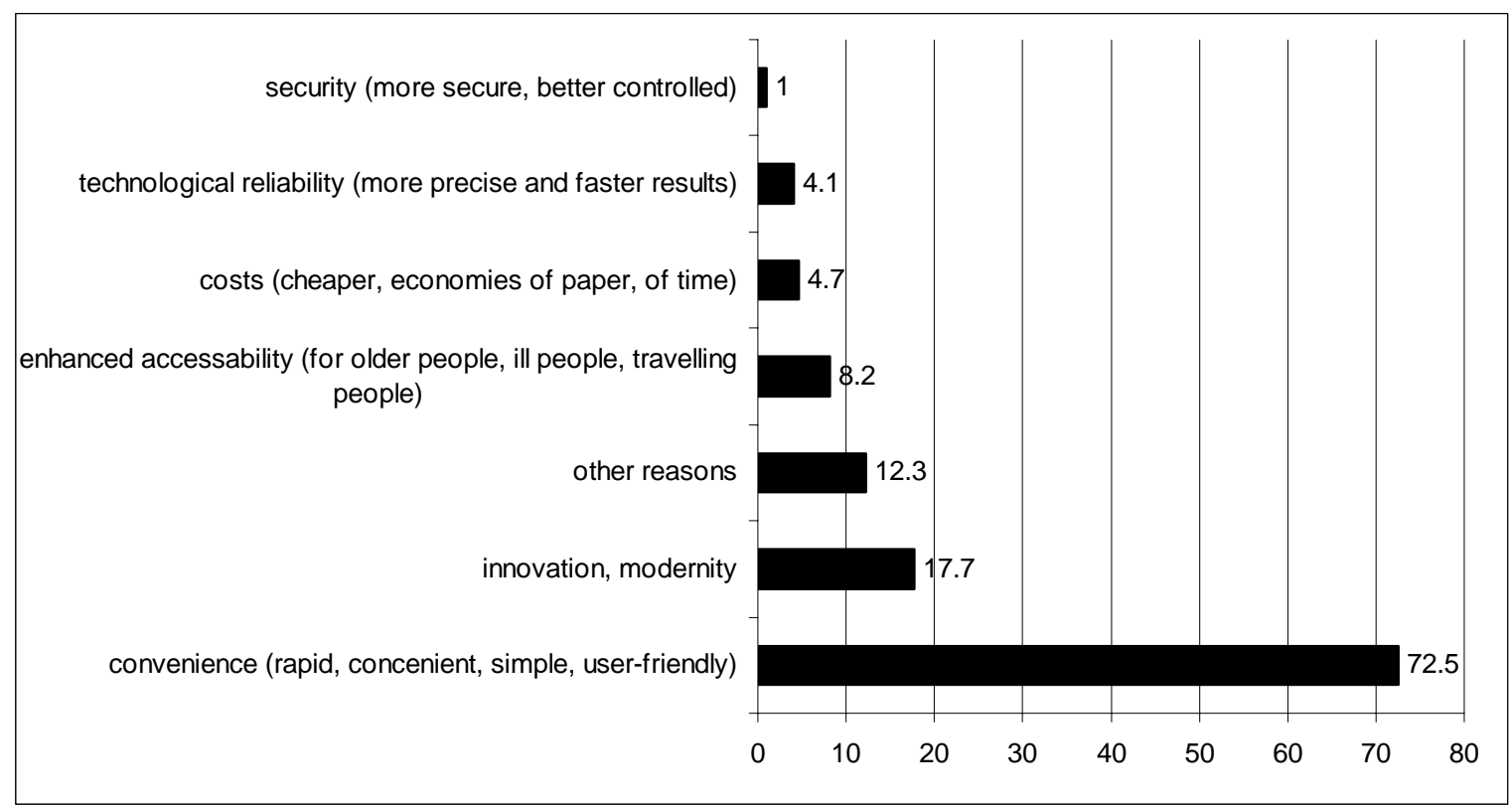

This last result is interesting insofar as it shows that internet voting corresponds, even in a context of very low cost procedures for democratic participation at the polls, to a demand for an even stronger reduction of the costs for remotely acceding the ballot box.

\section{The political effects of e-voting}

In this last section of our contribution we test whether or not this shift in modes of participation exerts a political effect. In other words, we are interested in finding out whether or not the introduction of e-voting procedures is politically neutral. In the preceding model explaining the choice for e-voting we have seen that all political 
variables remained insignificant. For example, one's political orientation, measured by the left-right scale, does not have any impact on the choice of e-voting over traditional forms of participation. The same goes if we cross party identification with the mode of vote (Figure 5).

Figure 5: Party identification and mode of participation

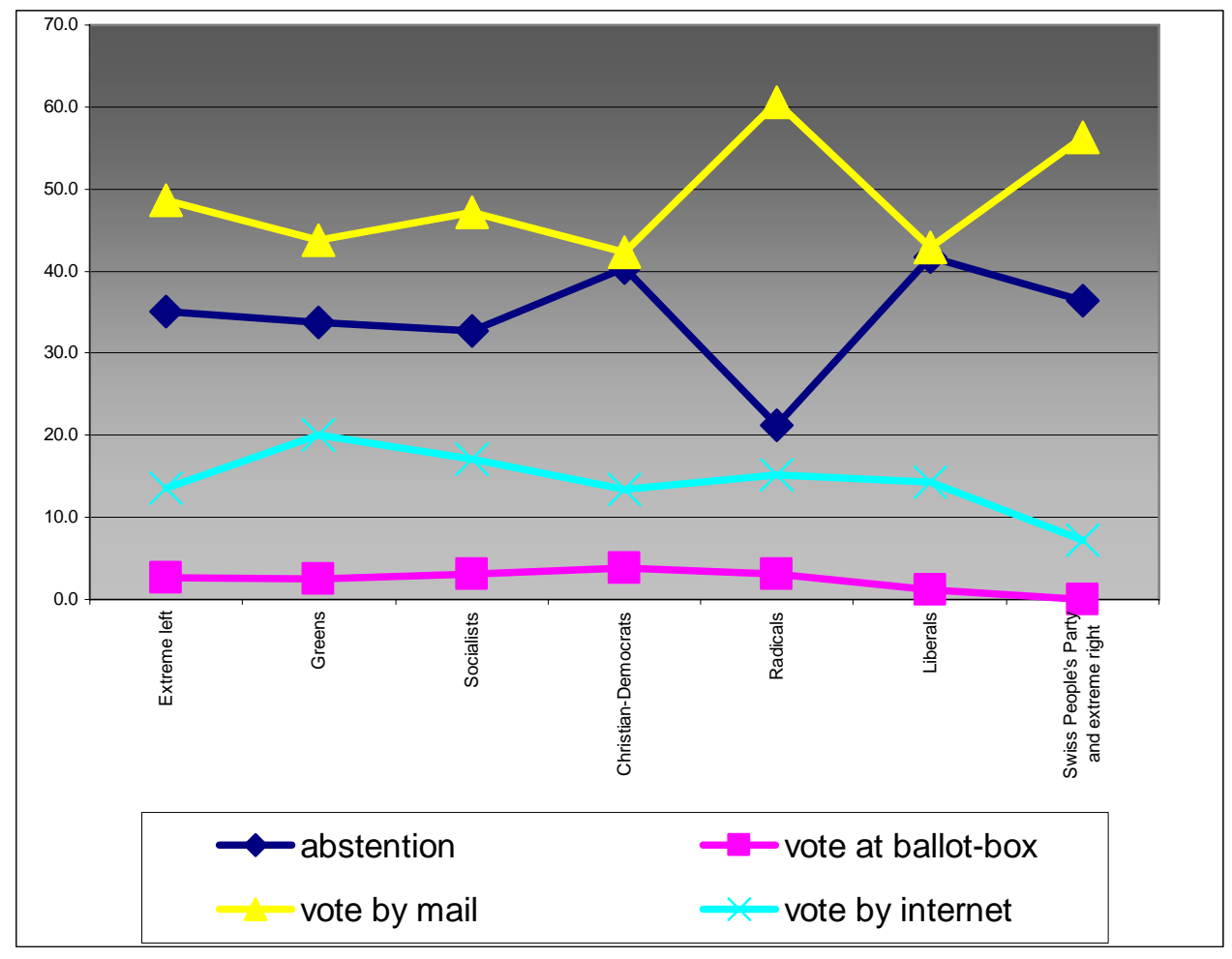

Figure 5 reveals three facts: first, no political party remained immune from the introduction of e-voting in the Canton of Geneva. A proportion of any party's sympathizers used this new means of participation. Second, sympathizers of the Green party - paradoxically the party that, in the parliamentary arena, strongly criticized the introduction of e-voting - were proportionally those who used e-voting most strongly (20 percent of Green party identifiers used e-voting compared to the average 15.4 percent of party identifiers). On the other side, this proportion gets as low as 7.3 percent for sympathizers of the Swiss People's Party and extreme right wing parties. Finally, excluding these two cases, the proportion of e-voters among all other party sympathizers is fairly similar. 
While these results may indicate that e-voting - if mobilizing further members of the electorate - may potentially bias (though only slightly) the outcome of future elections. However, e-voting may not necessarily (just yet?) lead to political distortions in the arena of direct democracy. In order to test this "political neutrality hypothesis" we have estimated a number of multivariate models, one for each issue that the Geneva voters decided upon on September 26 2004. The dependent variable in these models is codes $1=$ acceptance of the issue and $0=$ refusal of the issue at stake. Every model contains a series of socio-economic/demographic and political variables that we already used in the preceding models. In addition, we included a dummy-variable in the list of independent variables, distinguishing between e-voting and postal/polling-station voting. The results are contained in Tables 6 and 7 . 
Table 6: Explaining the outcome of four referendums on the federal level

\begin{tabular}{|c|c|c|c|}
\hline \multicolumn{4}{|c|}{ 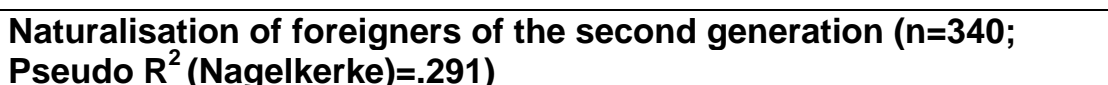 } \\
\hline Independent variables & $\mathrm{B}$ & s.e. & sig. \\
\hline Age (in 10-year categories) & -.055 & .104 & .600 \\
\hline Gender & .009 & .173 & .959 \\
\hline Level of education & -.177 & .325 & .586 \\
\hline Gross income of household & .118 & .062 & .058 \\
\hline Political discussions & -.195 & .172 & .258 \\
\hline Left-right scale & -1.048 & .153 & .000 \\
\hline Traditional voting/e-voting & .134 & .401 & .739 \\
\hline Constant & 4.753 & 1.048 & .000 \\
\hline \multicolumn{4}{|c|}{$\begin{array}{l}\text { Naturalisation of foreigners of the second generation }(n=338 ; \\
\text { Pseudo } R^{2} \text { (Nagelkerke)=.266) }\end{array}$} \\
\hline Independent variables & $\mathrm{B}$ & s.e. & sig. \\
\hline Age (in 10-year categories) & -.075 & .111 & .500 \\
\hline Gender & .231 & .181 & .202 \\
\hline Level of education & .081 & .334 & .809 \\
\hline Gross income of household & .067 & .064 & .297 \\
\hline Political discussions & -.228 & .179 & .204 \\
\hline Left-right scale & -.967 & .155 & .000 \\
\hline Traditional voting/e-voting & -.091 & .409 & .825 \\
\hline Constant & 4.165 & 1.062 & .000 \\
\hline \multicolumn{4}{|c|}{$\begin{array}{l}\text { Popular initiative "Postal services for everybody" ( } n=313 \text {; Pseudo } \\
R^{2} \text { (Nagelkerke)=.095) }\end{array}$} \\
\hline Independent variables & $\mathrm{B}$ & s.e. & sig. \\
\hline Age (in 10-year categories) & .063 & .088 & .469 \\
\hline Gender & -.363 & .153 & .018 \\
\hline Level of education & .381 & .268 & .155 \\
\hline Gross income of household & -.003 & .049 & .948 \\
\hline Political discussions & -.297 & .147 & .044 \\
\hline Left-right scale & -.329 & .112 & .003 \\
\hline Traditional voting/e-voting & .116 & .321 & .718 \\
\hline Constant & 2.769 & .879 & .002 \\
\hline \multicolumn{4}{|c|}{$\begin{array}{l}\text { Law on maternity-leave insurance }\left(n=340 ; \text { Pseudo } R^{2}\right. \\
\text { (Nagelkerke) }=.136)\end{array}$} \\
\hline Independent variables & $\mathrm{B}$ & s.e. & sig. \\
\hline Age (in 10-year categories) & .042 & .140 & .764 \\
\hline Gender & .282 & .222 & .204 \\
\hline Level of education & .083 & .416 & .843 \\
\hline Gross income of household & -.035 & .079 & .654 \\
\hline Political discussions & -.039 & .224 & .863 \\
\hline Left-right scale & -.698 & .178 & .000 \\
\hline Traditional voting/e-voting & .064 & .501 & .899 \\
\hline Constant & 3.766 & 1.306 & .004 \\
\hline
\end{tabular}

Note: in bold $=$ sign. at $95 \%$ level 
Table 7: Explaining the outcome of two referendums on the cantonal level

\begin{tabular}{|c|c|c|c|}
\hline \multicolumn{4}{|c|}{$\begin{array}{l}\text { Law on the commerce with alcoholic beverages }\left(n=327 ; \text { Pseudo } R^{2}\right. \\
\text { (Nagelkerke)=.035) }\end{array}$} \\
\hline Independent variables & $B$ & s.e. & sig. \\
\hline Age (in 10-year categories) & -.005 & .076 & .946 \\
\hline Gender & .051 & .126 & .684 \\
\hline Level of education & .293 & .234 & .210 \\
\hline Gross income of household & .045 & .043 & .303 \\
\hline Political discussions & -.015 & .127 & .904 \\
\hline Left-right scale & -.220 & .100 & .027 \\
\hline Traditional voting/e-voting & .052 & .278 & .853 \\
\hline Constant & -.610 & .715 & .394 \\
\hline \multicolumn{4}{|c|}{$\begin{array}{l}\text { Law on demolitions, transformations and renovations of buildings } \\
\text { for housing ( } n=263 \text {; Pseudo } R^{2} \text { (Nagelkerke)=.063) }\end{array}$} \\
\hline Independent variables & $\mathrm{B}$ & s.e. & sig. \\
\hline Age (in 10-year categories) & .165 & .094 & .080 \\
\hline Gender & .096 & .144 & .504 \\
\hline Level of education & -.324 & .278 & .243 \\
\hline Gross income of household & .065 & .051 & .204 \\
\hline Political discussions & -.143 & .157 & .363 \\
\hline Left-right scale & .186 & .112 & .095 \\
\hline Traditional voting/e-voting & -.083 & .339 & .806 \\
\hline Constant & -1.758 & .864 & .042 \\
\hline
\end{tabular}

Note: in bold $=$ sign. at $95 \%$ level

In none of the six models does the variable measuring the mode of participation have a significant impact on the voter's decision at the polls. Internet voting therefore is, in the context of the September 2004 referendums in Geneva and regarding their outcomes, politically neutral. ${ }^{7}$ Overall, our models rather poorly fit the data with a relatively small part of the dependent variables' variances being explained. This, however, does not alter our relevant finding, namely that the introduction of e-voting did not affect the outcome of the six referendum issues.

\footnotetext{
${ }^{7}$ Though our aim is not to explain why voters in the four communes under consideration accepted or refused the proposed ballot issues, let us nevertheless underline that in five out of six cases, the variable "left-right scale" produced significant estimates. Also, in four of these five cases, it was the sole variable that had a significant impact.
} 


\section{Conclusion}

This contribution tried to assess the impact of new channels for direct democratic decision making processes on turnout and referendum outcomes. Our results suggest that in a context where remote postal voting has become the standard way of participation, e-voting procedures do not alter turnout as much as they change the nature of participation, at least for an already important part of the electorate. This part of the active electorate has tried it out, repeatedly, and was convinced by this switch. Whether the proportion of e-voters will grow, remain the same or even decrease, only the future can tell. Should it remain the same - or grow - then we need to reflect upon some possible accompanying measures that are wanted, and some side-effects that may be less so.

It is important to note that the Chancellery of the Canton of Geneva deliberately offered a "pure" e-voting module to the electorate, i.e. the e-voting platform did not provide the e-voters with anything else than the possibility to vote. However, numerous recent contributions point out that internet voting may develop its most important effects only if is part of a wider e-democracy agenda through which voters are not only given the possibility to cast their vote, but may gather supplementary information about issues and parties, deliberate online, create political profiles of their own political attitudes and match them with those of candidates etc. (Kies and Kriesi 2005, Ladeur 2005, Schmitter 2005, Schmitter and Trechsel 2004, Trechsel and Mendez 2005). For those that believe that such developments may alter the quality of the citizens' democratic participation, the news that 20 percent of the electorate in a procedural context that is already open to the extreme should be good news. Without even introducing such normative elements, one may raise the question of whether traditional referendum and election campaign techniques may be affected by such a change in the nature of participation - and if so, how. If such a large part of the active voters exert their political rights online, it is a short step for us to imagine that political actors, such as parties, candidates, interest associations but also governments and Parliaments, will more frequently and more intensively try to reach out - online - to this segment of the electorate. Though not as effective as promised by some "cyberoptimists" of the past, "internet canvassing", when combined with online voting procedures, may well become an important part of a campaign in our modern, liberal democracies. However, and for the time being, one should remain prudent and, 
above all, avoid generalizations at a moment where these developments are still highly experimental, designed and conducted in most dissimilar contexts.

\section{References}

Christin, Thomas and Alexander H. Trechsel, 2005. Analyse du scrutiny du 26 septembre 2004 dans quatre communes genevoises (Anières, Carouge, Cologny et Meyrin), e-Democracy Centre (e-DC), University of Geneva. (unpublished manuscript).

Christin, Thomas and Raphaël Müller, 2002. Analyse quantitative du test Alpha Ter: Evaluation par questionnaire du système de vote par Internet, Research and Docmentation Centre on Direct Democracy (c2d), Unibersity of Geneva (unpublished manuscript, also available at http://www.ge.ch/evoting/doc/rapports/rapport_alphater_evoting.pdf).

Downs, Anthony, 1957. An Economic Theory of Democracy. New York: Harper and Row.

Franklin, Mark N., 2004. Voter Turnout and the Dynamics of Electoral Competition in Established Democracies since 1945. Cambridge: Cambridge University Press.

Gibson, Rachel K., 2005. "Internet voting and the European Parliament elections. Problems and prospects", pp. 29-59 in Alexander H. Trechsel and Fernando Mendez (eds.) The European Union and E-Voting. Addressing the European Parliament's Internet Voting Challenge, London: Routledge.

Karp, Jeffrey A. and Susan A. Banducci, 2000. Going Postal: How All-Mail Elections Influence Turnout, Political Behavior 22, 3: 223-239.

Kies, Raphaël and Hanspeter Kriesi, 2005. "Internet voting and opinion formation: the potential impact of a pre-voting sphere", pp. 147-165 in Alexander H. Trechsel and Fernando Mendez (eds.) The European Union and E-Voting. Addressing the European Parliament's Internet Voting Challenge, London: Routledge.

Kies, Raphaël and Alexander H. Trechsel, 2001. "Le contexte socio-politique", pp. 673 in Andreas Auer and Alexander H. Trechsel (eds.) Voter par Internet? Le projet e-voting dans le canton de Genève dans une perspective socio-politique et juridique, Basel, Genf/ München: Helbing \& Lichtenhahn.

Kriesi, Hanspeter and Alexander H. Trechsel, 2005. The Politics of Switzerland. Continuity and Change in a Consensus Democracy. Cambridge: Cambridge University Press (in print). 
Ladeur, Karl-Heinz, 2005. "e.-Voting: a new political institution for the network society? New life for an old democratic procedure", pp. 202-222 in Alexander H. Trechsel and Fernando Mendez (eds.) The European Union and E-Voting. Addressing the European Parliament's Internet Voting Challenge, London: Routledge.

Norris, Pippa, 2005. "e-Voting as the magic ballot for European Parliamentary elections? Evaluating e-voting in the light of experiments in UK local elections", pp. 60-90 in Alexander H. Trechsel and Fernando Mendez (eds.) The European Union and E-Voting. Addressing the European Parliament's Internet Voting Challenge, London: Routledge.

Norris, Pippa, 2001. Digital Divide. Civic Engagement, Information Poverty, and the Internet Worldwide. Cambridge: Cambridge University Press.

Olson, Mancur, 1965. The Logic of Collective Action. Public Goods and the Theory of Groups. Cambridge: Harvard University Press.

Riker, William H. and Peter C. Oredshook, 1968. "A Theory of the Calculus of Voting" American Political Science Review 62: 25-42.

Schmitter, Philippe C., 2005. "e-Voting, e-Democracy and EU-democracy: a thought experiment", pp. 187-201 in Alexander H. Trechsel and Fernando Mendez (eds.) The European Union and E-Voting. Addressing the European Parliament's Internet Voting Challenge, London: Routledge.

Schmitter, Philippe C. and Alexander H. Trechsel (eds.), 2004. The Future of Democracy in Europe. Trends, Analyses and Reforms. Strasbourg: Council of Europe Publishing.

Southwell, Priscilla L., 2004. "Five Years Later: A Re-Assessment of Oregon's Vote by Mail Electoral Process", PS 37, 1: 89-93.

Trechsel, Alexander H. and Fernando Mendez, 2005. The European Union and evoting. Upgrading Euro-elections", pp. 1-25 in Alexander H. Trechsel and Fernando Mendez (eds.) The European Union and E-Voting. Addressing the European Parliament's Internet Voting Challenge, London: Routledge.

Trechsel, Alexander H., Fernando Mendez and Raphaël Kies, 2003. "Remote voting via the Internet? The canton of Geneva pilot-project", pp. 181-194 in Dimitri Gritzalis (ed.) Secure Electronic Voting. Norwell, MA: Kluwer Academic Publishers. Wernli, Boris, 2001. Contraintes institutionnelles, influences contextuelles et participation aux élections fédérales en Suisse. Bern: Haupt. 


\section{Annex}

Table A1: The socio-economic and demographic model (log. regression coefficients)

\begin{tabular}{lccc}
\hline Independent variables & B & s.e. & sig. \\
\hline Age (in 10-year categories) & -.286 & .085 & .001 \\
Gender & .120 & .248 & .629 \\
Level of education & .152 & .136 & .263 \\
Gross income of household & .134 & .045 & .003 \\
\hline Constant & -.1843 & .661 & .005 \\
\hline Pseudo $\mathrm{R}^{2}$ (Nagelkerke):..104; $\mathrm{n}=411 ;$ in bold = sign. at the $95 \%$ level
\end{tabular}

Table A2: The political model (log. regression coefficients)

\begin{tabular}{lccc}
\hline Independent variables & B & s.e. & sig. \\
\hline Left-right scale & -0.135 & 0.133 & .308 \\
Political discussions & -0.073 & 0.101 & .471 \\
Trust in political institutions & -0.160 & 0.163 & .329 \\
Trust in politicians & 0.219 & 0.180 & .225 \\
Trust in public authorities & 0.095 & 0.196 & .629 \\
\hline Constant & -1.326 & .590 & .025 \\
\hline Pseudo $\mathrm{R}^{2}$ (Nagelkerke): .016; $\mathrm{n}=450 ;$ in bold $=$ sign. at the $95 \%$ level
\end{tabular}

Table A3: The ICT model (log. regression coefficients)

\begin{tabular}{lrrr}
\hline Independent variables & B & s.e. & sig. \\
\hline Computer literacy & .263 & .168 & .117 \\
Frequency of internet use & .197 & .075 & .009 \\
Site of internet access & .104 & .326 & .749 \\
Type of connection & .901 & .320 & .005 \\
Trust in information on the internet & -.159 & .248 & .522 \\
Trust in communications on the internet & .384 & .196 & .050 \\
Trust in transactions on the internet & -.270 & .169 & .110 \\
Trust in the e-voting procedure & 1.338 & .255 & .000 \\
\hline Constant & -2.008 & 1.208 & .096 \\
\hline
\end{tabular}

Pseudo $\mathrm{R}^{2}$ (Nagelkerke): .348; $\mathrm{n}=277$; in bold = sign. at the $95 \%$ level 